\title{
Near real-time routine for volcano monitoring using infrared satellite data
}

\author{
Valerio Lombardo ${ }^{\star}$, Malvina Silvestri, Claudia Spinetti
}

Istituto Nazionale di Geofisica e Vulcanologia, Centro Nazionale Terremoti, Rome, Italy

\author{
Article history \\ Received November 12, 2010; accepted July 26, 2011. \\ Subject classification: \\ Remote sensing, Volcano monitoring, NOAA-AVHRR, Hot-spot detection, Lava-flow effusion rate.
}

\section{ABSTRACT}

An Advanced Very-High-Resolution Radiometer (AVHRR) routine for hotspot detection and effusion rate estimation (AVHotRR) using AVHRR infrared space-borne images is presented here for the monitoring of active lava flow. AVHotRR uses directly broadcast National Oceanic and Atmospheric Administration (NOAA)-AVHRR remotely sensed data. The 2006 summit eruption of Mount Etna provided the opportunity to test the products generated by AVHotRR for monitoring purposes. Low spatial and high temporal resolution products can also be used as inputs of flow models to drive numerical simulations of lava-flow paths and thus to provide quantitative hazard assessment and volcanic risk mitigation.

\section{Introduction}

Over the last twenty years, infrared (IR) remote sensing techniques for extracting volcanologically useful information have been used to study thermal structures of hot volcanic features, such as lava flows, lava lakes, volcanic domes, pyroclastic flows and fumaroles [Rothery et al. 1988, Crisp and Baloga 1990b, Harris et al. 1999, Wright et al. 2000].

On the one hand, detection of new thermal anomalies, or of changes in existing ones, can be of particular value for hazard evaluation. The activity during an effusive volcanic eruption can change rapidly over periods of minutes to hours as new lava flows erupt or develop. The destructive potential of these phenomena makes rapid information regarding their occurrence and development essential for hazard monitoring, assessment and response. Thus satellite-based radiometers that provide thermal data at high temporal resolution ( $>1$ image per day) are suitable for the monitoring of effusive eruptions if analyzed timely. These instruments provide data in which effusive events are easily detectable and where changes in the style and extent of the activity can be identified despite the low (1-25 $\mathrm{km}^{2}$ pixel) spatial resolution of the data [e.g. Harris et al. 1997a, Harris et al. 1997b, Wooster and Rothery 1997]. Furthermore, these data can be acquired directly from suitable receiving stations, and then processed within minutes of reception. Such near real-time information can be provided to monitoring agencies for volcanic hazard assessment.
On the other hand, thermal measurements can identify anomalies that are potentially related to the physical processes that trigger eruptions. Remotely sensed data have been used to estimate heat and mass fluxes of active lava flows. The movement of lava flows is a complex subject that has provoked debate regarding the mechanisms that control the areal extent and physical character of the flow [e.g. Pieri and Baloga 1986, Lipman and Banks 1987, Oppenheimer 1991, Oppenheimer 1993, Oppenheimer et al. 1993a, Oppenheimer et al. 1993b, Harris et al. 1997a, Harris et al. 1997b, Harris et al. 1998, Harris et al. 1999, Lombardo and Buongiorno 2006, Lombardo et al. 2006, Lombardo et al. 2009]. Progress has been made in the construction of useful mathematical models [e.g. Crisp and Baloga 1990a, Pieri et al. 1990, Oppenheimer 1993, Harris et al. 1997a, Harris et al. 1997b, Harris et al. 1998, Harris et al. 1999, Lombardo et al. 2009]. The determination of volumetric effusion rates for lava flows from space is an important, but challenging, task. Effusion rates are a major consideration in the evaluation of flow dynamics and of the potential threat posed by a lava flow. Higher effusion rates produce channelfed flows that are longer, more rapidly moving, more voluminous, and more extensive than flows with low effusion rates [Walker 1973, Wadge 1977, Pieri and Baloga 1986]. Flows with high effusion rates thus have far greater potential to inflict damage on distant communities with less advance warning. The measurement of effusion rates is therefore of great interest. Field methods for their determination are usually based on estimates of the lavachannel dimensions and the lava-flow velocity [e.g. Lipman and Bancks 1987, Barberi et al. 1993]. However, errors due to uncertainties in channel dimensions are a major problem, especially for lava depth. Alternatively, if the eruption duration is known, accurate post-eruption measurements of total lava flow-field volumes can provide reliable estimates of average effusion rates [e.g. Calvari et al. 1994]. However, these averages will not reveal the major variations in the effusion rates that have been shown to occur during many basaltic eruptions [Wadge 1981]. 
In spite of their original aims, meteorological sensors have been increasingly used for operational monitoring of the thermal features of a volcano. Satellite systems include the Eumetstat Meteosat Second Generation (MSG) Spinning Enhanced Visible and Infrared Imager (SEVIRI) [Ganci et al. 2011], the National Oceanic and Atmospheric Administration (NOAA) Geostationary Operational Environmental Satellites (GOES) [Harris et al. 2001], the NASA Moderate Resolution Imaging Spectroradiometer (MODIS) [Wright et al. 2004], the European Space Agency (ESA) Along Track Scanning Radiometer (ATSR) [Colin et al. 2007], and the NOAA Advanced Very High Resolution Radiometer (AVHRR) [Webley et al. 2008, Marchese et al. 2011]. The widely used AVHRR sensor represents a good compromise between spatial resolution and measurement frequency, with the possibility of equipping satellite receiving stations at volcanology institutes [Harris et al. 1997b].

Different approaches have been adopted for the identification of thermal activity using AVHRR data. The robust satellite techniques provide hot-spot detection [Pergola et al. 2004], through computation of a statistical index in the medium IR (MIR) spectral band using a multiyear time series data of the same area.

\section{NOAA/AVHRR: the INGV satellite receiving station}

Satellite receiving stations allow real-time tracking and reception of polar orbiter and geostationary satellites [Spinetti et al. 2010]. At the Istituto Nazionale di Geofisica e Vulcanologia (INGV), the station installed in Rome (Figure 1a) at the end of 2004 comprises an L-band receiving antenna of $0.46 \mathrm{~m}$ diameter with high-resolution picture transmission telemetry. The station is a Terascan $($ system (SeaSpace), which integrates hardware and software for automated reception of data and pre-processing of AVHRR data from the U.S. NOAA polar constellation. Twice-daily planned global coverage is provided by NOAA TIROS-N satellites that operate in parallel in near-polar sun synchronous orbits at a height of about 850 $\mathrm{km}$. The NOAA satellites that were active during the 2006 and 2008 Mount Etna lava flow were: NOAA-12, NOAA-14, NOAA-15, NOAA-16, NOAA-17, NOAA-18. Although NOAA-19 was not active in 2008, it is now operative, and for completeness, its characteristics are included in Table 1.

\begin{tabular}{lcc}
\hline AVHRR & NOAA 12, 14 & NOAA 15,16, 17, 18, 19 \\
\hline Channel 1 (VIS) & $0.58-0.68 \mu \mathrm{m}$ & $0.58-0.68 \mu \mathrm{m}$ \\
Channel 2 (NIR) & $0.725-1.1 \mu \mathrm{m}$ & $0.725-1.1 \mu \mathrm{m}$ \\
Channel 3A (MIR) & $3.55-3.9 \mu \mathrm{m}$ & $3.55-3.9 \mu \mathrm{m}$ \\
Channel 3B (MIR) & - & $1.58-1.64 \mu \mathrm{m}$ \\
Channel 4 (TIR) & $10.3-11.3 \mu \mathrm{m}$ & $10.3-11.3 \mu \mathrm{m}$ \\
Channel 5 (TIR) & $11.4-12.4 \mu \mathrm{m}$ & $11.4-12.4 \mu \mathrm{m}$ \\
\hline
\end{tabular}

Table 1. AVHRR spectral sensor characteristics.

The satellite pass over the Mediterranean is tracked for the area showed in Figure 1b. The corresponding data cover from the north of Europe to the north of Africa, and from eastern Europe to Spain.
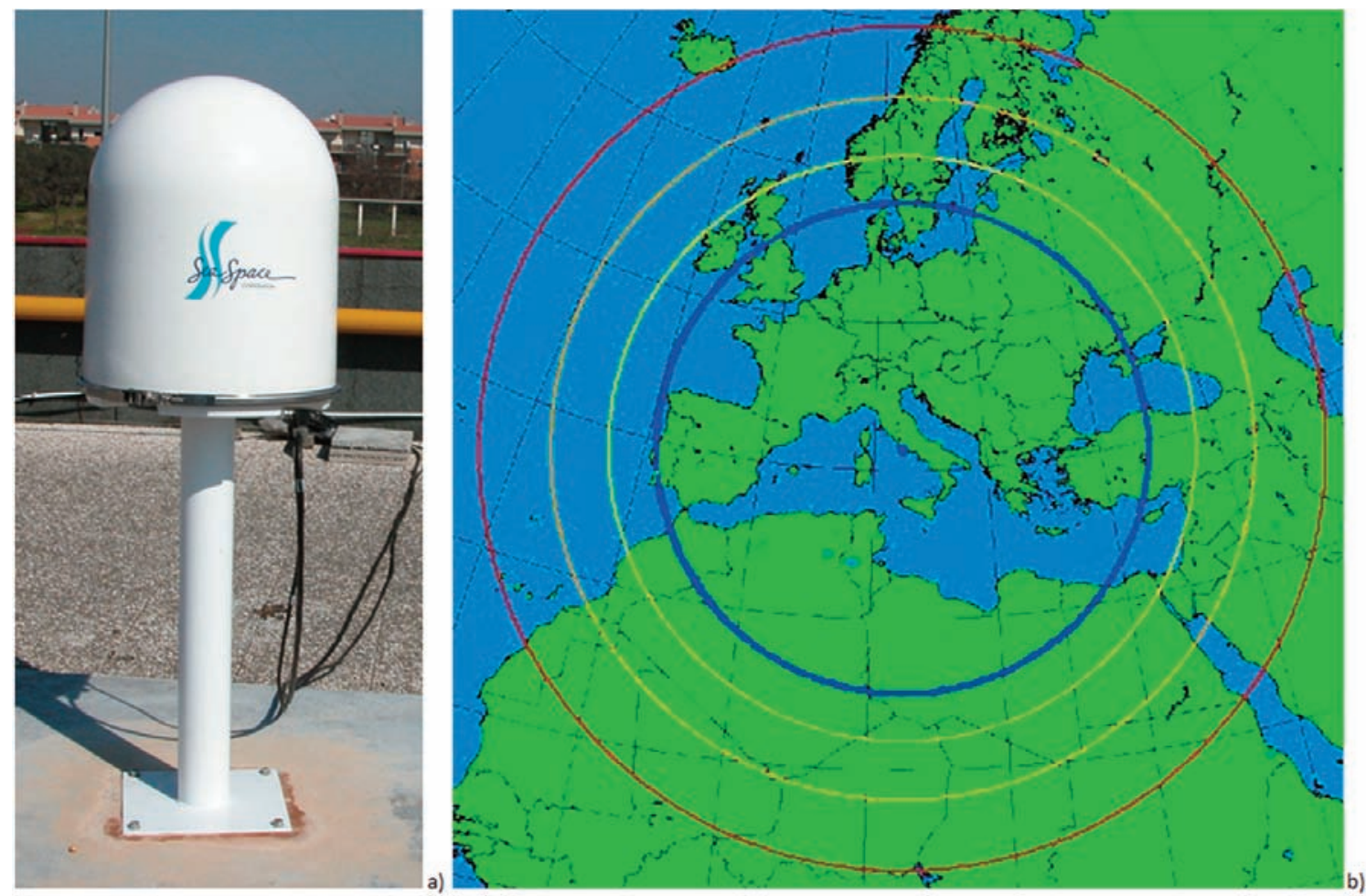

Figure 1. a) Photograph of the receiving antenna with radome installed on the roof of the INGV building, Rome. b) The inner blue circle represents the area of data acquisition in view of the L-band antenna located in Rome (blue point). 
The primary sensor on board the NOAA polar-orbiting satellites is the AVHRR imager spectrometer. This instrument records the radiation from the Earth and atmosphere at different wavelengths, from visible to thermal IR (TIR) (Table 1). The AVHRR/2 on board NOAA-12 and NOAA-14 have five channels. The AVHRR/3 on NOAA-15, NOAA-16, NOAA-17, NOAA-18 and NOAA-19 have six channels: five are the same as for AVHRR/2, while channel 3 has been split into channels $3 \mathrm{~A}$ and $3 \mathrm{~B}$. Channel $3 \mathrm{~B}$ operates during the night-time portion of the orbit. Channel $3 \mathrm{~A}$ has a different wavelength range, and operates during the daylight portion of the orbit. The instrument has an instantaneous field-of-view of 1.3 milliradians, which provides a nominal spatial resolution for the nadir view of $1.1 \mathrm{~km}$. A continuously rotating elliptical scan mirror provides the cross-track scan from \pm 55.4 degrees from the nadir.

The temporal coverage of the Italian territory comprises at least four passes by day. The constellation of NOAA allows a high repetition rate. The combination of the spatial resolution and spectral capabilities makes this sensor useful and widely used for the monitoring of volcanic activity, and in particular for the monitoring of the Etnean lava flow.

The summit of the Mount Etna volcano has been predefined by a geographic mask. All of the NOAA passes that cover this area are stored on a dedicated machine.

For the high temperature values in the AVHRR images, the IR channel saturation is at $47.5{ }^{\circ} \mathrm{C}, 50{ }^{\circ} \mathrm{C}$ and $60{ }^{\circ} \mathrm{C}$ for bands 3, 4 and 5, respectively.

\subsection{AVHRR data pre-processing}

The AVHRR antenna acquires data in real-time that comes from the NOAA satellites and sends these to a dedicated workstation (Figure 2). Through the internet, this workstation periodically downloads the AVHRR calibration coefficients from the SeaSpace website. Then, the acquired data in Terascan $₫$ data format (TDF; as used in this system) are automatically converted into hierarchical data format (HDF), as a more compatible format. Once the HDF data have been produced, they are stored in a dedicated directory and sent by file-transfer protocol (FTP) to different directories [Silvestri et al. 2008].

\section{Dual-band-technique background}

The pixel dimensions of satellite data often exceed the width of lava bodies. Where a pixel is wider than the hot feature, three-component models are more realistic: the first component corresponds to the cooler, solidified crust of the flow, the second component corresponds to the fractures in the crust that are representative of the molten or plastic flow of he interior, and the third component corresponds to the 'cold' surrounding ground. However, because the number of unknowns (temperatures) far exceeds the number of

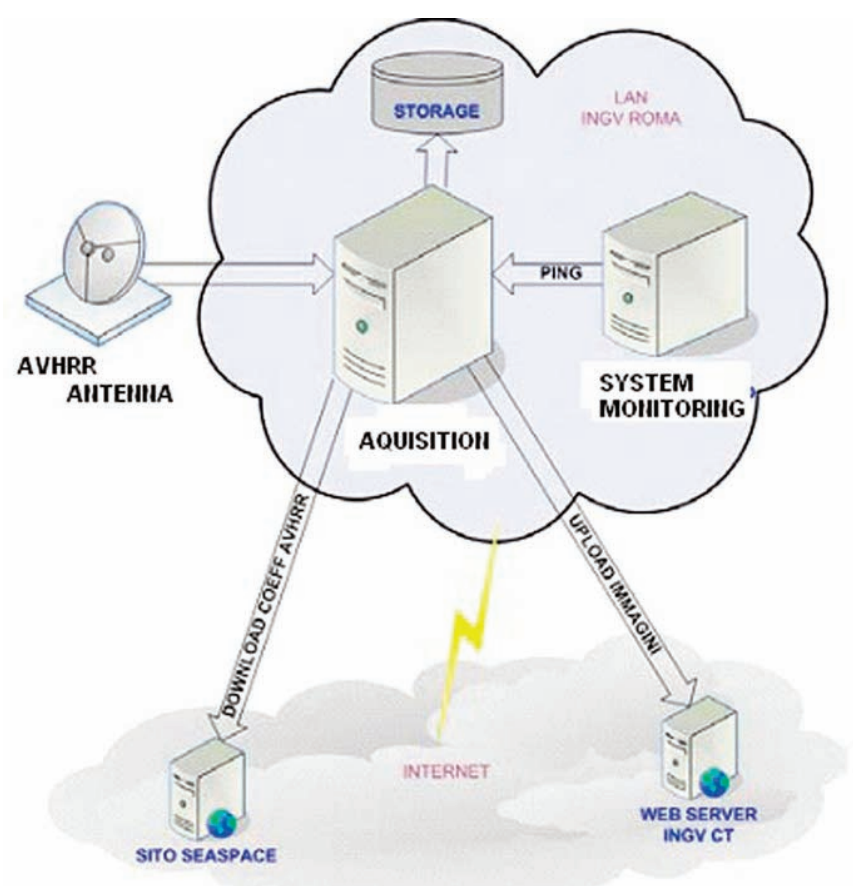

Figure 2. AVHRR data acquisition set-up.

equations (bands), three-thermal-component models require several critical assumptions to be satisfied. Two different approaches have been developed to solve this problem: 1) reducing the number of thermal components used in the model; and 2) constraining the three-component models using any available 'ground truth'. These two approaches are described in the next two sections.

\subsection{The dual-band technique}

using a two-thermal-component model

The widely accepted cooling model for AVHRRdetected lava flows considers the thermal flux as a function of the fractional area of two thermally distinct radiant surfaces: the surface occupied by the lava at temperature $T_{h}$, and the remaining area that represents the cooler background at the ambient temperature $T_{b}$. The radiance detected by the sensor in one $\mathrm{x}$-th band $\mathrm{L}\left(\mathrm{T}_{\mathrm{x}} \lambda_{\mathrm{x}}\right)$ is an average, weighted by the fractional area, of the two radiances $\mathrm{L}\left(\mathrm{T}_{\mathrm{h}} \lambda_{\mathrm{x}}\right)$ and $\mathrm{L}\left(\mathrm{T}_{\mathrm{b}} \lambda_{\mathrm{x}}\right)$, which are related to the two temperatures given by the following equation:

$$
\mathrm{L}\left(\mathrm{T}_{\mathrm{x}} \lambda_{\mathrm{x}}\right)=\varepsilon \tau \cdot\left[\mathrm{f}_{\mathrm{h}} \mathrm{L}\left(\mathrm{T}_{\mathrm{h}} \lambda_{\mathrm{x}}\right)+\left(1-\mathrm{f}_{\mathrm{h}}\right) \mathrm{L}\left(\mathrm{T}_{\mathrm{h}} \lambda_{\mathrm{x}}\right)\right]
$$

where $f_{h}$ is the fractional area of the lava component, and $\varepsilon_{\mathrm{x}}$ and $\tau_{\mathrm{x}}$ are the lava emissivity and atmospheric transmittance in band $\mathrm{x}$, respectively. Using two IR wavelength bands, Equation (1) can be split into a equation system of two unknown temperatures (see Equation 4). We can solve the system using one short-wave IR (SWIR)/MIR band to characterize the hottest component lava body $\left(T_{h}\right)$, and one TIR band $(8-12 \mu \mathrm{m})$ for the cooler background $\left(T_{b}\right)$. This is the so-called dual-band technique that can be applied to a 


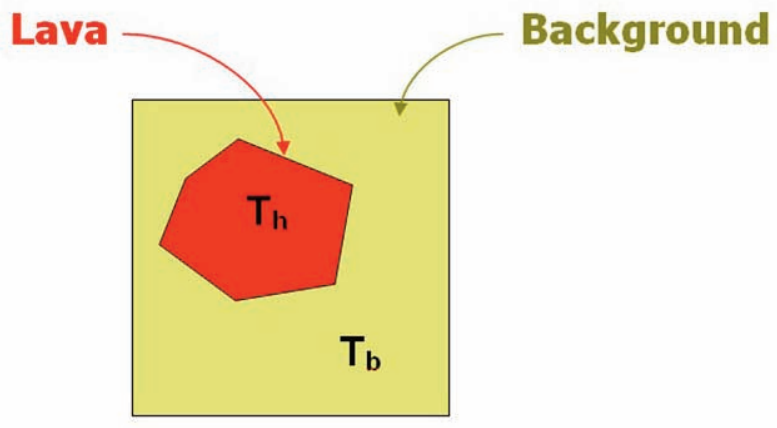

Figure 3. The dual-band method. This assumes that a pixel is occupied by two thermal components: a high-temperature component at temperature $T_{h}$ that occupies a portion $f_{h}$ of the pixel, surrounded by a cooler component at temperature $T_{b}$ that occupies the remainder $\left(1-f_{h}\right)$ of the pixel.

\section{Crust}

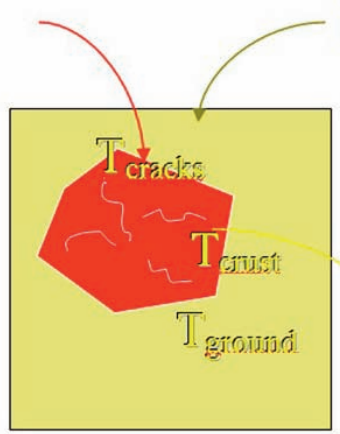

Figure 4. The three-thermal-component model. This is characterized by three distinct sub-pixel temperatures: $T_{h}$, crack temperature; $T_{c}$, crust temperature, and $\mathrm{T}_{\mathrm{b}}$, ground temperature.

two-thermal-component model using low-spatial-resolution data (Figure 3).

Usually, this technique allows the estimation of $T_{h}$ and $f_{h}$, if $T_{b}$ is assumed. It is possible to estimate the background temperature from the non-radiant pixels around the lava body if the background emissivity is known. The sub-pixel lava temperature retrieved will, of course, be an average value between the crust and the molten lava temperatures.

\subsection{The dual-band technique}

\section{using a three-thermal-component model}

An active lava body of $c a .1 \mathrm{~km}^{2}$ of pixel area will be occupied by at least three components: molten lava at temperature $T_{h}$ that will occupy a portion $f_{h}$ of the pixel, the chilled crust (which forms rapidly on the exposed molten lava) at temperature $T_{c}$ that will occupy fc of the pixel, and the lava-free ground surface at $T_{b}$ that will occupy the remainder of the pixel area: $1-f_{h}-f_{c}$ (Figure 4$)$.

Therefore Equation (1) has been adapted to include a third component on $\mathrm{x}$-th and $\mathrm{y}$-th bands:

$$
\begin{aligned}
& \mathrm{L}\left(\mathrm{T}_{\mathrm{x}} \lambda_{\mathrm{x}}\right)= \\
& \varepsilon_{\mathrm{x}} \tau_{\mathrm{x}}\left[\mathrm{f}_{\mathrm{h}} \mathrm{L}\left(\mathrm{T}_{\mathrm{h}} \lambda_{\mathrm{x}}\right)+\mathrm{f}_{\mathrm{c}} \mathrm{L}\left(\mathrm{T}_{\mathrm{c}} \lambda_{\mathrm{x}}\right)+\left(1-\mathrm{f}_{\mathrm{h}}-\mathrm{f}_{\mathrm{c}}\right) \mathrm{L}\left(\mathrm{T}_{\mathrm{b}} \lambda_{\mathrm{x}}\right)\right]
\end{aligned}
$$

$$
\begin{aligned}
& \mathrm{L}\left(\mathrm{T}_{\mathrm{y}} \lambda_{\mathrm{y}}\right)= \\
& \varepsilon_{\mathrm{y}} \tau_{\mathrm{y}}\left[\mathrm{f}_{\mathrm{h}} \mathrm{L}\left(\mathrm{T}_{\mathrm{h}} \lambda_{\mathrm{y}}\right)+\mathrm{f}_{\mathrm{c}} \mathrm{L}\left(\mathrm{T}_{\mathrm{c}} \lambda_{\mathrm{y}}\right)+\left(1-\mathrm{f}_{\mathrm{h}}-\mathrm{f}_{\mathrm{c}}\right) \mathrm{L}\left(\mathrm{T}_{\mathrm{b}} \lambda_{\mathrm{y}}\right)\right]
\end{aligned}
$$

There are five unknowns, $f_{h}, f_{c}, T_{h}, T_{c}$ and $T_{b}$ in these two simultaneous equations (Equations 2a, 2b). To constrain a reasonable model, valid and unique estimates are required for at least three of these parameters. We therefore assume $T_{h}$ and estimate $T_{b}$, as for Equations (2a) and (2b), with $T_{h}$ set to $1,000{ }^{\circ} \mathrm{C}$ and $T_{b}$ estimated from the adjacent 'lava-free' pixels. This leaves three unknowns, $f_{h}, f_{c}$ and $T_{c}$. Field and satellite data show that the temperatures for $T_{c}$ can range over several hundreds of degrees Celsius, making $T_{c}$ impossible to define using a single value [Oppenheimer 1991, Flynn and MouginisMark 1994]. To avoid the error that would be introduced by selecting a single $T_{c}$, we chose to solve Equations (2a) and (2b) over a reasonable range of $T_{c}$, to give a range of solutions within which the true solution must lie. Following the results of Oppenheimer [1991] and Flynn et al. [1993], we selected $100{ }^{\circ} \mathrm{C}$ as a reasonable lower limit for the $T_{c}$ range. $T_{c}$ will have an upper limit, above which $f_{h}$ needs to become negative to solve Equations (2a) and (2b). This approach gives maximum values for $T_{c}$ typically between $150{ }^{\circ} \mathrm{C}$ and $350{ }^{\circ} \mathrm{C}$, with estimates of up to $470{ }^{\circ} \mathrm{C}$ in extreme cases [Harris et al. 1997b].

\section{The AVHotRR routine}

The AVHotRR routine has been developed for hot-spot detection and effusion rate estimation using AVHRR IR space-borne images. The AVHotRR routine is composed of graphical user-interface procedures that are implemented in interactive data language (IDL), which takes advantage of the functionality of the environment for visualizing images (ENVI) environment for image managing/processing. AVHotRR allows for automatic hot-spot detection of each near real-time received data from the storage machine. When there is positive detection of a lava flow, the routine automatically estimates the total thermal flux and the effusion rate. The flow chart in Figure 5 describes the AVHotRR functionality.

The first version of the AVHotRR routine was used during the entire 2006 Mount Etna eruption, to provide daily lava-flow effusion rates to the INGV volcanological observatory and the Department of Civil Protection [Spinetti et al. 2008]. A second version of the software was developed within the Sistema Rischio Vulcanico project, funded by the Italian Space Agency in the framework of the National Space Plan 2003-2005, under the Earth Observation section for natural-risk management. The software was finally improved within the LAVA project.

\subsection{Cloud mask}

The cloudiness identification is essential to volcanic monitoring for two reasons: first, clouds have a critical role in hot-spot detection, as they can significantly decrease the 

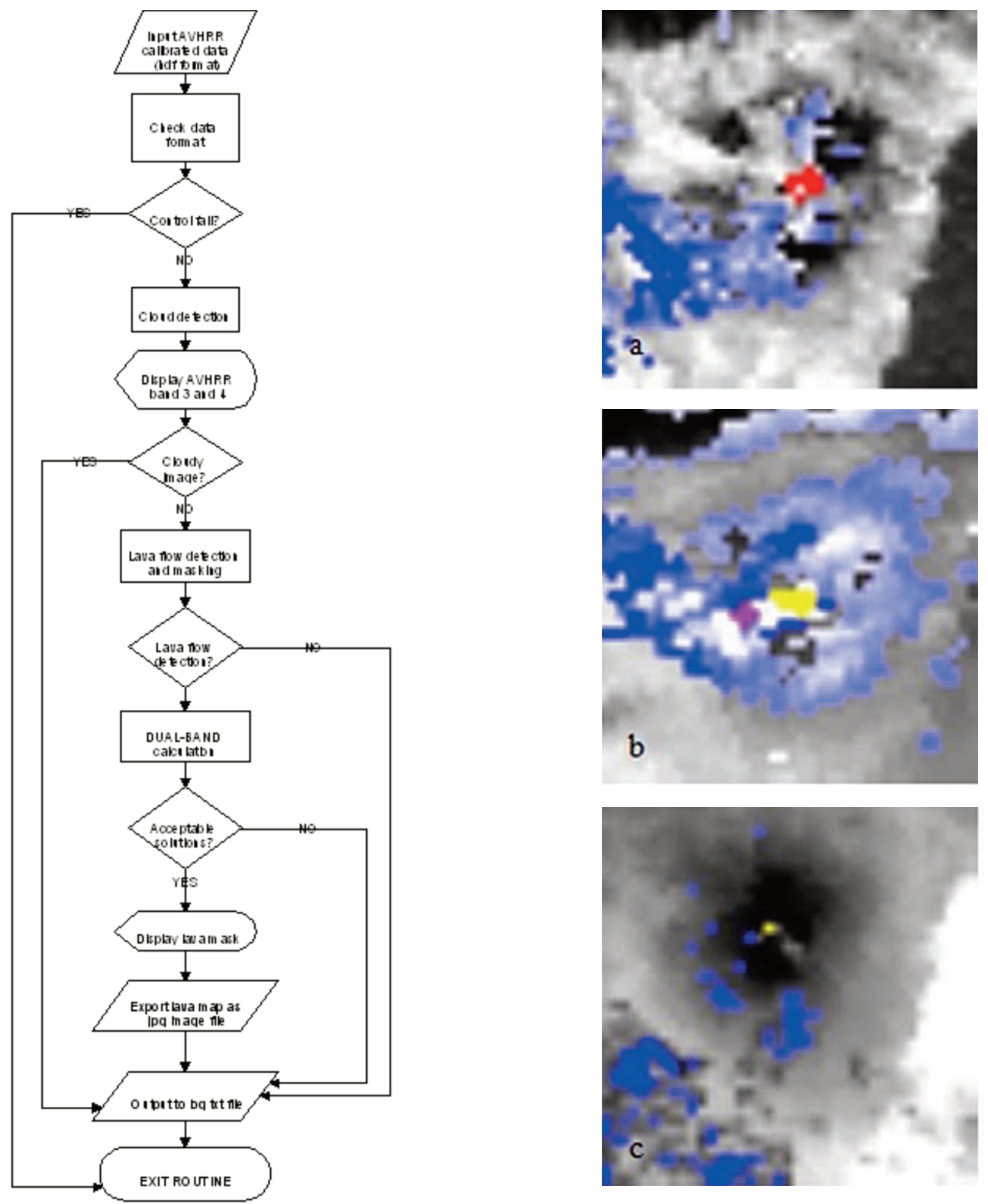

Figure 5 (left). The AVHotRR flow chart. Figure 6 (right). Cloud mask examples for the Etna 2006 eruption. (a) Day time, July 20, 2006. (b) Day time, July 22, 2006. (c) Night-time August 8, 2006. Blue pixels, cloudy areas; red pixels, radiant hot-spots; yellow pixels, saturated hot-spots.

satellite IR signals. For this reason, the cloudiness must be accurately masked, to assess any thermal anomaly identification. Second, the presence of cloudiness near a hotspot can distort the background temperature, $T_{b}$. In this case, the cloud-contaminated pixel areas must be accurately determined to correctly retrieve the radiant contribution from potential thermal anomalies. For many of the retrieval algorithms, even thin cirrus cloud represents a contamination.
The cloud detection mask proposed by Chen et al. [2002] was implemented for day-time images, while a modified version of the algorithm that was developed by Spangerberg et al. [2002] was used for night-time images. These algorithms have been adapted according to the seasonal conditions of Mount Etna (e.g. snow in winter). Figure 6 shows examples of the AVHotRR output with cloud masks. 


\subsection{Hot-spot detection}

The automatic 'hot-spot-detection' procedure uses AVHRR data hat are directly acquired using the NOAA/Terascan station. Hot-spot detection is part of the AVHotRR system that was previously developed in the framework of ASI-SRV project. AVHotRR automatically scans the AVHRR data and sends an alert when thermal anomalies are detected by the procedure (Figure 7 ). The procedure is based on the theoretical solution of the 'dualband' system of equations, which are performed using a digital filter to single out hot radiant pixels, as proposed by Lombardo et al. [2004] for Landsat TM SWIR bands. The filter was initially developed for detection of volcanic hotspots, and then it was adapted to allow detection of different thermal anomalies, including active lava flow. This algorithm was adapted for AVHRR band $3(\operatorname{Rad} 3)$ and $4(\operatorname{Rad} 4)$, assuming a two-thermal-component model for active lava flow. The first part of the filter builds on the assumption that the fractional areas are greater than zero. The following experimental formula is used to cut off the values of radiance that do not satisfy the condition of positive fractional area:

$$
\operatorname{Rad} 3>0.161096 * \operatorname{Rad} 4
$$

The second part of the filter satisfies the condition that the sub-pixel lava temperature is greater than zero:

$$
\operatorname{Rad} 3<\operatorname{Rad} 4 *\left(0.0238096 * \mathrm{~T}_{\mathrm{L}}-4.81817\right)
$$

where $T_{L}$ is the average integrated temperature of the lava. A $\mathrm{T}_{\mathrm{L}}$ of $500{ }^{\circ} \mathrm{C}$ has been identified as the most fit value for Etnean flows.

\subsection{The dual-band technique}

The sub-pixel temperature retrieval technique is pivotal in the remote sensing of active lava flows. A two-thermalcomponents model was chosen to keep the system as independent as possible of auxiliary information. The algorithm uses the globally convergent Broyden method to solve the dual-band-equation system:

$$
\mathrm{L}\left(\mathrm{T}_{\mathrm{x}} \lambda_{3}\right)=\varepsilon_{3} \tau_{4}\left[\mathrm{f}_{1} \mathrm{~L}\left(\mathrm{~T}_{1} \lambda_{3}\right)+\left(1-\mathrm{f}_{1}\right) \mathrm{L}\left(\mathrm{T}_{\mathrm{b}} \lambda_{3}\right)\right]
$$
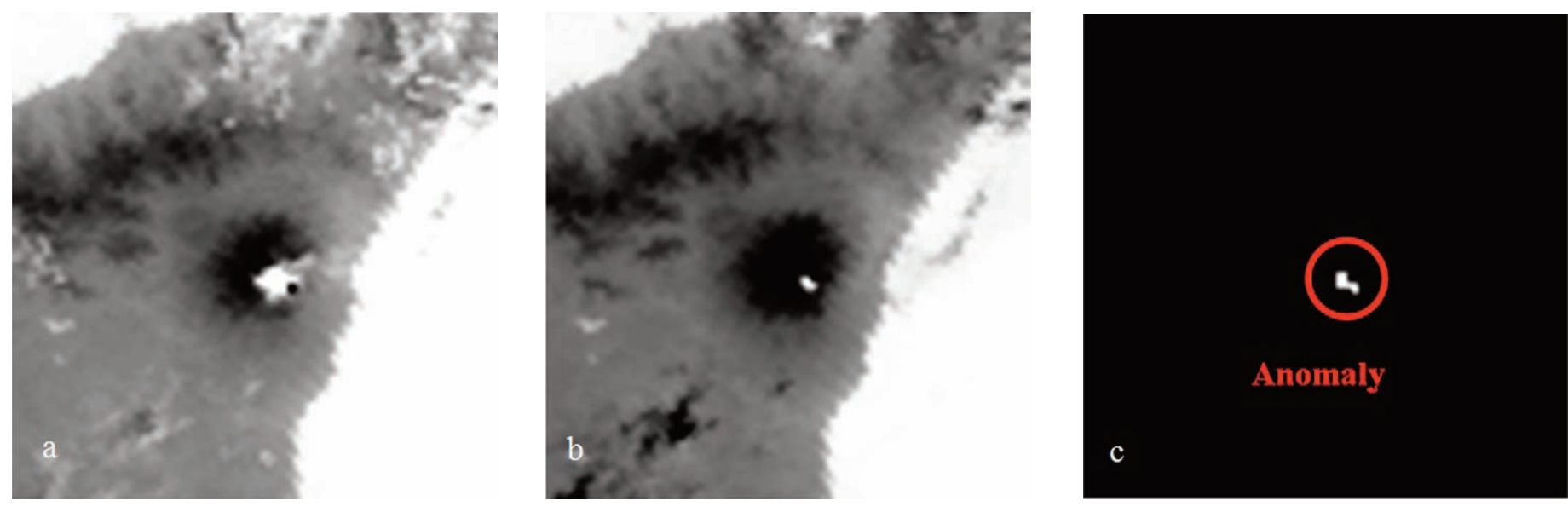

Figure 7. Mount Etna eruptive activity imaged by AVHRR during the 2006 eruption. (a) In MIR band 3. (b) In TIR band 4. (c) Hot-spot detection generated by AVHotRR.
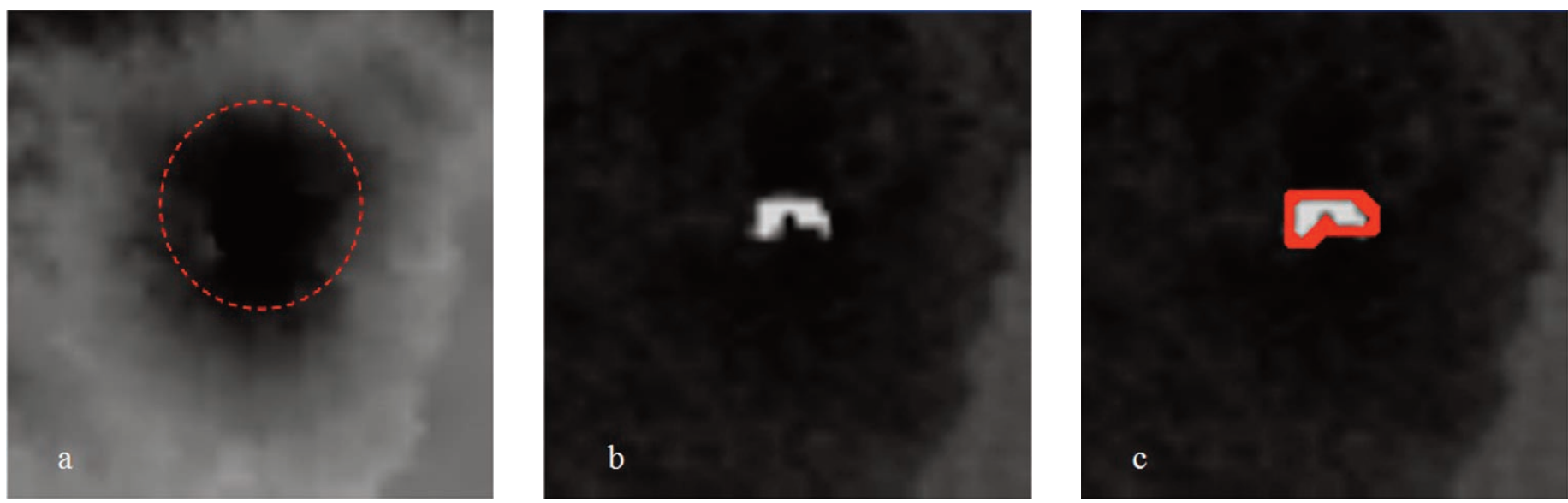

Figure 8. Mount Etna AVHRR image of October 30, 2006. (a) Crater area (darkest pixels), characterized by an almost uniform distribution of basaltic flows. (b) Thermal anomaly in band 3. (c) Thermal anomaly contour for the background-temperature estimation from the non-active pixels surrounding the thermal anomaly. 


$$
\mathrm{L}\left(\mathrm{T}_{\mathrm{x}} \lambda_{4}\right)=\varepsilon_{4} \tau_{4}\left[\mathrm{f}_{1} \mathrm{~L}\left(\mathrm{~T}_{1} \lambda_{4}\right)+\left(1-\mathrm{f}_{1}\right) \mathrm{L}\left(\mathrm{T}_{\mathrm{b}} \lambda_{4}\right)\right]
$$

where $L$ is the Planck function for a blackbody radiating to temperature $T$ and at wavelength $\lambda, T_{x}$ and $T_{y}$ are the pixelintegrated temperatures from Equations (2a) and (2b) in AVHRR bands 3 and 4, respectively, $\varepsilon$ is the spectral emissivity, and $\tau$ is the atmospheric transmittance [Wan and Dozier 1989].

The dual-band approach requires assumed knowledge of the values of one of the three unknowns: lava temperature $\left(\mathrm{T}_{\text {lava }}\right)$, background temperature $\left(T_{b}\right)$ or fraction of pixel occupied by the lava $\left(f_{\text {lava }}\right)$.

AVHotRR derives $T_{b}$ from the non-active pixels surrounding the thermal anomaly, under the assumption of known background emissivity.

A relatively uniform surface of basaltic lavas characterizes the Mount Etna summit area (Figure $8 \mathrm{a}$ ). Therefore, $T_{b}$ can be estimated assuming a suitable $\varepsilon$ for Etnean cold basalts. As $T_{b}$ can vary widely from the vent to the flow toe, the AVHotRR retrieves the maximum $\left(\mathrm{T}_{\mathrm{bmax}}\right)$ and minimum $\left(\mathrm{T}_{\mathrm{bmin}}\right)$ temperatures of the background in a pixel mask (Figure $8 \mathrm{~b}$, c). Dual-band solutions $\left(\mathrm{T}_{\text {lava }}\right.$ and $\mathrm{f}_{\text {lava }}$ ) are then calculated for every $T_{b}$ between $T_{b \min }$ and $T_{b \max }$. Figure 9 shows the $T_{\text {lava }}$ and $f_{\text {lava }}$ trends plotted as functions of $T_{b}$ in a temperature range of $0{ }^{\circ} \mathrm{C}$ to $10{ }^{\circ} \mathrm{C}$ for a hot pixel of the October 30,2006 , lavaflow AVHRR image on Mount Etna.

Logarithmic and linear trend models appear to best fit the $\mathrm{T}_{\text {lava }}$ versus $\mathrm{T}_{\mathrm{b}}$ and $\mathrm{f}_{\text {lava }}$ versus $\mathrm{T}_{\mathrm{b}}$ distributions, respectively. These models are in agreement with models that are derived from theoretical solutions of the dual-band system of equations [Glaze et al. 1989, Oppenheimer 1993, Lombardo et al. 2004, Lombardo and Buongiorno 2006, Lombardo et al. 2006]. Standard deviations (SDs) of $1{ }^{\circ} \mathrm{C}$ and $10^{-3}$ were obtained for $\mathrm{T}_{\text {lava }}$ and $\mathrm{f}_{\text {lava }}$, respectively. Statistics over a large number of samples highlight that a larger SD can occur for re-sampled pixels and for pixels affected by blurring due to the presence of volcanic plumes in the scene.

Therefore, the SDs of $\mathrm{T}_{\text {lava }}$ and $\mathrm{f}_{\text {lava }}$ can be used as extra tools to determine the accuracy of the parameters retrieved. Figure 10 shows the $\mathrm{T}_{\text {lava }}$ and $\mathrm{f}_{\text {lava }}$ trends obtained from a rejected lava pixel. In this case, SDs of $19{ }^{\circ} \mathrm{C}$ and $4 \times 10^{-2}$ were obtained for $\mathrm{T}_{\text {lava }}$ and $\mathrm{f}_{\text {lava }}$, respectively. The AVHotRR performs logarithmic and linear best fits of $T_{\text {lava }}$ and $f_{\text {lava }}$, respectively, and automatically rejects pixels according to a confidence threshold of the SDs.

\subsection{Estimation}

of the energy flux radiated by an active lava flow

The energy produced by an active lava flow is lost to the environment through a combination of conduction, convection and radiation. TIR remote sensing research has focused on inferring information from the radiative component, as the convective and conductive components
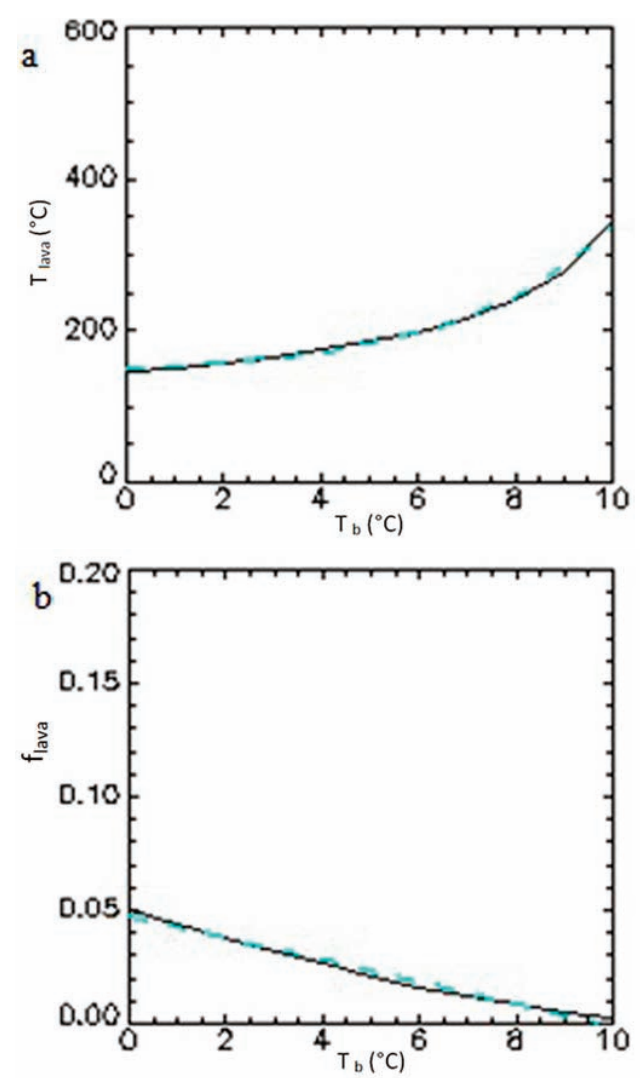

Figure 9. (a) $T_{\text {lava }}$ and (b) $f_{\text {lava }}$ trends as functions of $T_{b}$, for a radiant pixel on the AVHRR image of Mount Etna on October 30, 2006. Black solid line, solution from the dual-band fit; blue dashed line, solution from the logarithmic linear fit.
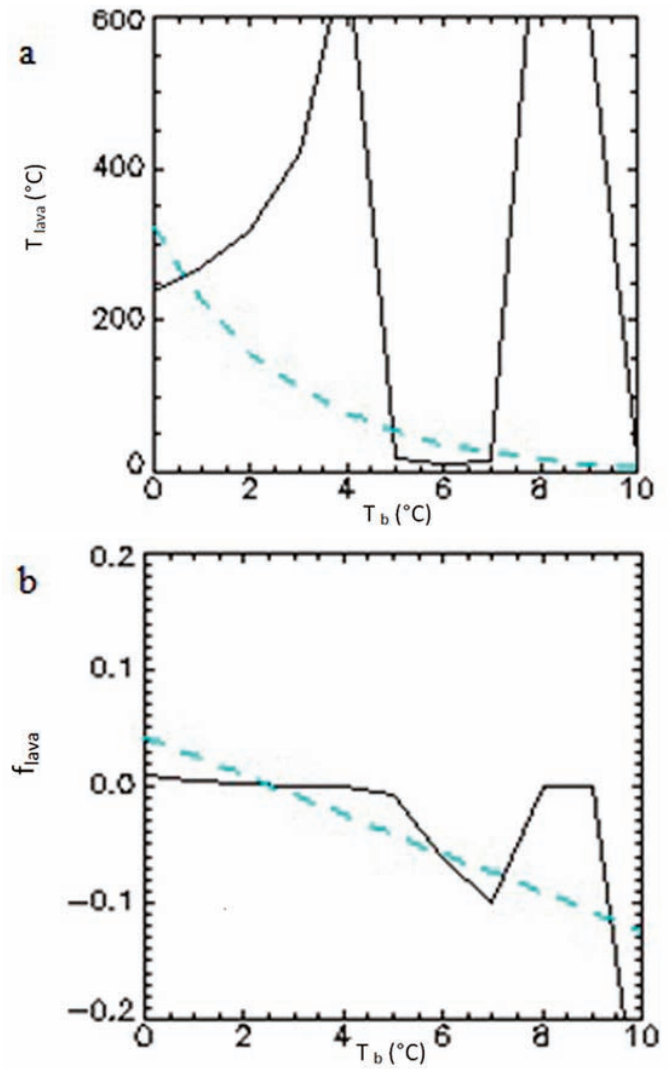

Figure 10. (a) $T_{\text {lava }}$ and (b) $f_{\text {lava }}$ trends as a functions of $T_{b}$, for a rejected radiant pixel of the AVHRR image of Mount Etna on October 30, 2006. Black solid line, solution from the dual-band fit; blue dashed line, solutions from the logarithmic linear fit. 
are difficult to quantify directly. The radiative transfer components of the observed scene of a lava flow are very complex: in the same area there are zones that are not yet overwhelmed by the lava flow, and here are burning zones and zones already burnt; in the burning zones at least two distinct lava-flow stages need to be considered, as flaming and smoldering, which are characterized by different temperatures and emission rates. Moreover, the atmospheric loading is very complex too, with the presence of hot gases, including water vapor, and often with ash emissions.

In general, the retrieval of lava parameters from space is based on simplified radiative-transfer models that are often referred as Dozier models [Dozier 1981].

In this approach, the pixel is seen as a composite target made up of two 'gray-body' targets that are linearly combined through coefficients that represent a fraction of the hot and cold parts, with respect to the whole of the pixel. This model restricts the observation of the active lava flow to the MIR and TIR emission bands. Indeed, according to the Wien displacement law, the peak of the surface emitted radiance shifts to shorter wavelengths as the surface temperature increases. So, temperatures of about $1,000{ }^{\circ} \mathrm{C}$ can give significant signal contributions in the SWIR region, where there are emission and reflection phenomena and where a more complex model is needed to interpret the satellite data.

Following Oppenheimer [1991] and Harris et al. [1997a, 1997b, 1998, 2000], and assuming that the heat loss can be described by a simple model for a subaerial channel-fed flow, the total flux $Q_{\text {tot }}$ is:

$$
Q_{\text {tot }}=Q_{\text {rad }}+Q_{\text {conv }}+Q_{\text {cond }} .
$$

$Q_{\text {rad }}, Q_{\text {conv }}$ and $Q_{\text {cond }}$ are the total radiant, the convective, and the conductive heat fluxes, respectively. The $Q_{\text {rad }}$ for each pixel that contains active lava $\left(Q_{r a d(p)}\right)$ is calculated using:

$$
Q_{\text {rad( }(p)}=\varepsilon \sigma \mathrm{A}_{\mathrm{p}}\left[f_{\text {lava }} \mathrm{T}_{\text {lava }}{ }^{4}+\left(1-f_{\text {lava }}\right) \mathrm{T}_{\mathrm{b}}{ }^{4}\right]
$$

in which $\varepsilon$ is the emissivity ( 0.98 for basalts), $\sigma$ is the StefanBoltzmann constant $\left(5.67 \times 10^{-8} \mathrm{~W} \mathrm{~m}^{-2} \mathrm{~K}^{-4}\right)$, and $\mathrm{A}_{\mathrm{p}}$ is the AVHRR pixel area. The total radiative heat loss is then obtained by summing $Q_{\text {rad(p) }}$ for every lava pixel. $Q_{\text {conv }}$ is estimated for the entire lava-flow field in a similar way, where $Q_{\text {conv }}$ for each pixel of the image that contains active lava $\left(Q_{\text {conv }(p)}\right)$ is calculated using the free convection case given by Harris et al. [1997b, 1998]. This reduces to:

$$
Q_{\text {conv }(p)}=\mathrm{h}_{\mathrm{c}}\left[\mathrm{T}_{\text {surf }}-\mathrm{T}_{\text {air }}\right]
$$

in which $h_{c}$ is the convective heat transfer coefficient, $T_{\text {surf }}$ is the lava surface temperature, and $\mathrm{T}_{\text {air }}$ is the ambient air temperature, where the values given in Harris et al. [1997b] result in an $\mathrm{h}_{\mathrm{c}}$ of $5 \mathrm{~W} \mathrm{~m}^{-2} \mathrm{~K}^{-1}$ to $12 \mathrm{~W} \mathrm{~m}^{-2} \mathrm{~K}^{-1}$ for free convection. This is a theoretically calculated value for free convection [see Harris et al. 2005], whereas values for forced convection obtained from measurements [Keszthelyi et al. 2003] and modeling [Patrick et al. 2005] indicate higher values of $\mathrm{h}_{\mathrm{c}}\left(c a .50 \mathrm{~W} \mathrm{~m}^{-2} \mathrm{~K}^{-1}\right)$. The heat conducted through the base of the flow is given by [Harris et al. 1997b]:

$$
Q_{\text {cond }}=\mathrm{A}_{\mathrm{p}} \mathrm{k} \delta \mathrm{T} / \delta \mathrm{h}
$$

where $\mathrm{k}$ is $2.5 \mathrm{~W} \mathrm{~m}^{-1} \mathrm{~K}^{-1}$ to $3.2 \mathrm{~W} \mathrm{~m}^{-1} \mathrm{~K}^{-1}, \delta \mathrm{T}$ is $520 \mathrm{~K}$ (assuming a core temperature of $1100{ }^{\circ} \mathrm{C}$ and a basal contact temperature of $580{ }^{\circ} \mathrm{C}$ ), and $\delta \mathrm{h}$ is $0.2 \mathrm{~m}$ (hot model) or 3.0 $\mathrm{m}$ (cold model). This accounts for $c a .25 \%$ of the total heat loss $\left(\mathrm{Q}_{\mathrm{tot}}\right)$.

In reality, the assumptions involved mean that the main variable is the active lava area $\left(A_{\text {lava }}\right)$, so that the above steps define the slope of a linear relationship between the effusion rate and lava-flow area [Wright et al. 2001].

\subsection{Transformation of the energy flux} into the mass flux for effusion-rate estimation

The effusion rate and flow volume are important controls of the lava-flow morphological parameters and lavaflow length [Walker 1973, Wadge 1977, Kilburn 1990, Kilburn and Guest 1993]. Following Pieri and Baloga [1986], it is commonly assumed that the lava flow is effectively stationary at the moment of the image capture. For a thermally unmixed case, the effusion rate $\mathrm{E}_{\mathrm{r}}$ is given by the following equation:

$$
E_{r}=\frac{\mathrm{Q}_{\mathrm{rad}}+\mathrm{Q}_{\text {conv }}+\mathrm{Q}_{\text {cond }}}{\rho\left[\mathrm{C}_{\mathrm{p}} \Delta \mathrm{T}+\varphi \mathrm{C}_{\mathrm{L}}\right]}
$$

where $Q_{\text {rad }}, Q_{\text {conv }}$ and $Q_{\text {cond }}$ are the total radiant, the convective, and the conductive heat fluxes, respectively, $\rho$ is the lava density, $\mathrm{C}_{\mathrm{p}}$ is the specific heat capacity, $\Delta \mathrm{T}$ is the average temperature drop throughout the active flow (equal to the initial eruption temperature minus the temperature at which the forward movement of the lava ceases), $\varphi$ is the average mass fraction of crystals grown in the cooling for $\triangle \mathrm{T}$, and $\mathrm{C}_{\mathrm{L}}$ is the latent heat of crystallization. Pieri and Baloga [1986] derived a simpler model, in which $Q_{c o n v}$ and $Q_{\text {cond }}$ in Equation (5) are not considered. For the Etnean flow, we use $\rho$ and $\mathrm{C}_{\mathrm{p}}$ of $2,600 \mathrm{~kg} \mathrm{~m}^{-3}$ and $1,150 \mathrm{~J} \mathrm{~kg}^{-1} \mathrm{~K}^{-1}$, respectively [Kilburn and Guest 1993]. The $\Delta \mathrm{T}$ is not likely to be greater than the difference between the eruption temperature and the solidus temperature of the lava. We used the maximum temperature measured in the flow, i.e. $1,080{ }^{\circ} \mathrm{C}$ (S. Calvari, personal communication, 1996) for the eruption temperature. Since the differences between the liquid and solidus ranges from $150{ }^{\circ} \mathrm{C}$ to $200{ }^{\circ} \mathrm{C}$ for most magmas [Archambault and Tanguy 1976], we chose a solidus temperature of $c a .900{ }^{\circ} \mathrm{C}$. The maximum amount of crystallization ranges from 0.4 to 0.5 , which allows for $30 \%$ initial phenocrysts and $20 \%$ to $30 \%$ 

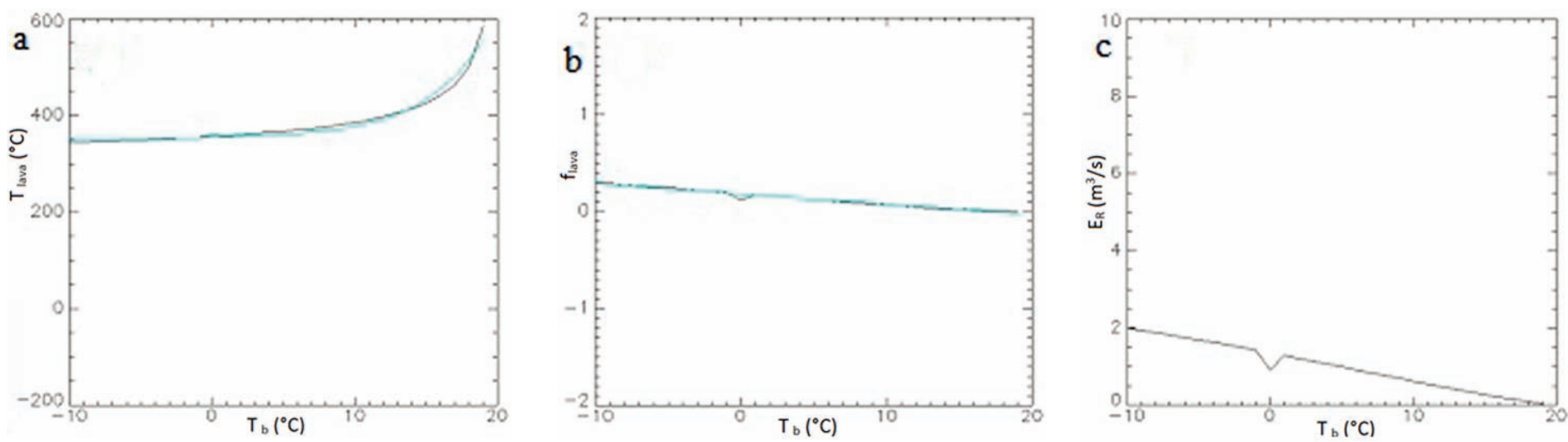

Figure 11. (a) $\mathrm{T}_{\text {lava }}$ and (b) $\mathrm{f}_{\text {lava }}$ solutions, (c) as retrieved for a single lava pixel for $\mathrm{Er}_{\mathrm{Max}}$ and $\mathrm{Er}_{\mathrm{Min}}$.

residual glass in the solid lava [Armienti et al. 1994]. The latent heat of crystallization $\left(\mathrm{C}_{\mathrm{L}}\right)$ is $2.9 \times 10^{5} \mathrm{~J} \mathrm{~kg}$, as given by Huppert and Sparks [1988].

As $\mathrm{T}_{\mathrm{b}}$ ranges between $\mathrm{T}_{\mathrm{bmin}}$ and $\mathrm{T}_{\mathrm{bmax}}, Q_{\text {rad }}$ varies between a minimum $\left(\mathrm{Q}_{\min }\right)$ and a maximum $\left(\mathrm{Q}_{\max }\right)$, while $\mathrm{T}_{\text {lava }}, \mathrm{f}_{\text {lava }}$ are given by Equation (4). In the same way, $Q_{\text {cond }}$ is given by Equation (8), as the hot and cold models. As a consequence, we derive $\mathrm{E}_{\mathrm{r}}$ from Equation (9), which spans a range from $\mathrm{E}_{\mathrm{rMax}}$ to $\mathrm{E}_{\mathrm{rMin}}$ (Figure 11).

\section{Outputs}

The AVHotRR automatic procedure provides hot-spot information using a system of e-mail alerts (Figure 12). The alert messages give information about the number of hotspots, the number of radiant pixels, and eventually, the cloud contamination.

The effusion rates and other information are automatically written into an ASCII file, to allow further analysis of the eruptive time-series. Within the LAVA project, the 2006 Mount Etna eruption was chosen as case study to test and validate the results derived from different sensors and techniques.
The resumption of activity at Mount Etna occurred in mid-July 2006, when a short fissure opened on the southeast crater (SEC) cone, which released a lava flow that traveled $3.5 \mathrm{~km}$ eastwards over the following 10 days [Neri et al. 2008]. An intermitted lava flows occurred at the SEC from September to mid-October, 2006, with an increase of paroxysmal activity [Andronico et al. 2009]. Between midOctober and mid-December, 2006, persistent lava outflow occurred from a vent at 2,800 $\mathrm{m}$ in altitude on the upper eastern flank of Mount Etna. This vent showed strong fluctuations in its effusion rate that were correlated with the paroxysmal episodes [Behncke et al. 2009].

A total of 479 AVHRR images of Mount Etna were acquired from June to December, 2006. Figure 13 shows the statistics for the processed data.

Figure 13A shows the percentages of the images where hot-spots were detected. In all, 39\% of our dataset showed hot-spot detection, and 38\% showed 'no-activity' detection, using the filter described in Equation (3). The remaining 23\% of the images were rejected as false positives, according to the number of hot-spots detected. Specifically, AVHotRR

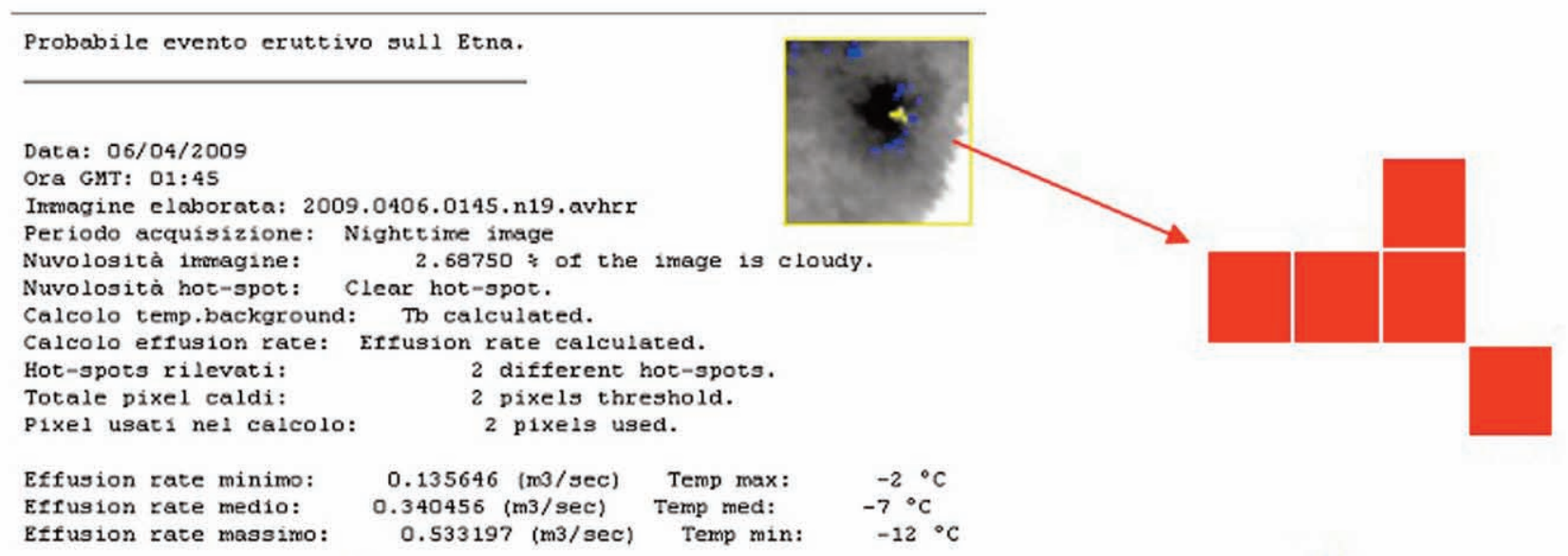

a)

Figure 12. Example of alert message. (a) Text message, and (b) image and number of pixels detected. 
A

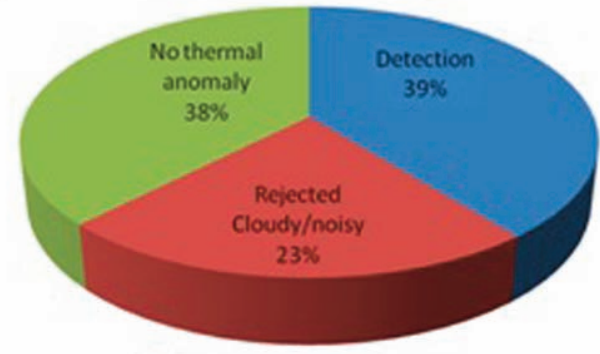

B

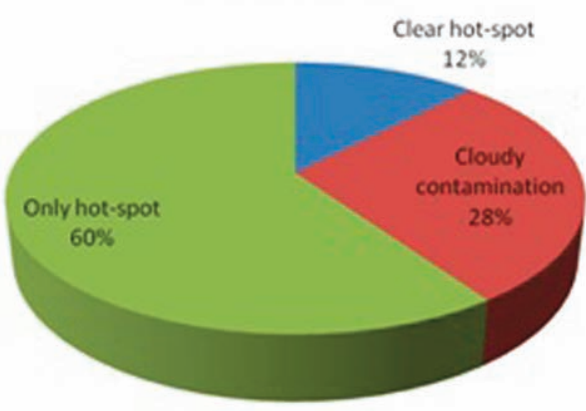

C

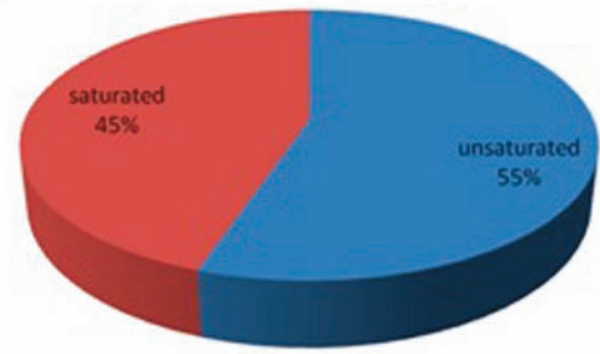

rejects the alerts with more than 10 hot-spots. Comparisons between our data and field observations indicated the following: $7 \%$ false negatives that were due to the thick cloud cover that obscured the hot-spot emissions (which were thus not detectable by any of the systems); $5 \%$ false negatives that were due to the hot-spot number threshold (e.g. for more than 10 hot-spots, with at least one of them real); and 3\% false positives due to noisy or cloudy images.

Figure 13B shows the statistics of the detected hot-spots: $12 \%$ of the images were cloud-free hot-spots, where the effusion rate was correctly calculated; $28 \%$ of the images had cloud contamination, where the effusion rates might be distorted; and $60 \%$ of the images had very cloudy images. While the hot-spot was identified, the effusion-rate calculation failed.

Finally, Figure 13C shows the statistics of the saturated pixels. Saturation of the AVHRR data mainly occurred in band 3. Lombardo et al. [2004] demonstrated that the dualband system is still solvable when using one saturated band. However, the retrieved temperatures will be unpredictably underestimated.

Figure 14 shows the derived minimum and maximum effusion rates for this 2006 eruption. The difference between the minimum and maximum values gives the error in the effusion rate estimation. A mean error of $36 \%$ in the effusion

Figure 13 (left). Pie chart statistics for (A) detection, (B) cloudiness, and (C) sauration for the hot-spots analyzed from the AVHRR data for the Mount Etna eruption from June to December, 2006. Figure 14 (below). AVHRR-derived maximum (red) and minimum (blue) effusion rates for the 2006 Mount Etna eruption.

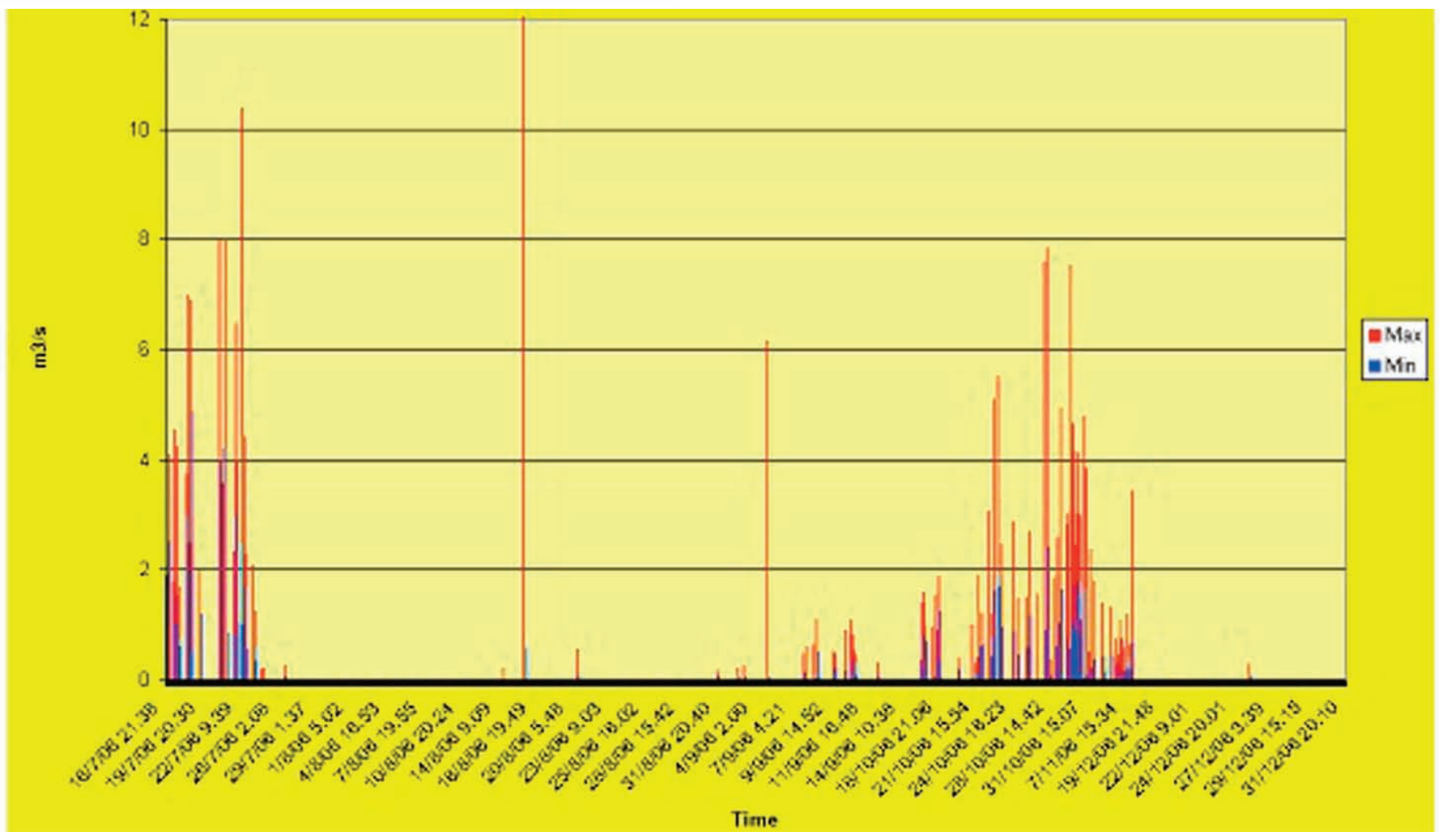


rate estimation was found over the entire period of this 2006 eruption of Mount Etna.

\section{Conclusions}

AVHotRR is a robust routine that allows hot-spot detection and effusion-rate estimation. The LAVA project, which is funded by the Italian Department of Civil Protection, represents a unique opportunity to integrate the procedures developed in AVHotRR with the data from the scientific activities, which greatly improved the accuracy of the algorithms and the values retrieved. The multi-approach method that was adopted in the framework of the LAVA project integrates the AVHRR effusion rate that is derived with effusion rates from other sensors for very high temporal-resolution analysis and monitoring of active lava flows. The products generated by AVHotRR and other analogous procedures that use MODIS and MSG-SEVIRI data can be used as the input to flow models (e.g. MAGFLOW) [Vicari et al. 2009], to drive numerical simulations of lava-flow paths, and thus to provide quantitative hazard assessments and volcanic risk mitigation.

Acknowledgements. This study was carried out in the framework of the V3-LAVA project (Lava flow invasion hazard map at Mt. Etna and methods for its dynamic update), funded by the Department of Civil Protection in the INGV-DPC 2007-2009 agreement. We are grateful to Dr. Chiara Cardaci and Dr. Maria Fabrizia Buongiorno. Our thanks also go to the two anonymous reviewers who helped us to improve our manuscript, and to Dr. Laura Colini for her helpful review of our manuscript.

\section{References}

Andronico, D., C. Spinetti, A. Cristaldi and M.F. Buongiorno (2009). Observations of Mt. Etna volcanic ash plumes in 2006: an integrated approach from ground-based and polar satellite monitoring system, J. Volcanol. Geoth. Res., 180, 135-147; doi: 10.1016/j.jvolgeores.2008.11.013.

Archambault, C. and J.C. Tanguy (1976). Comparative temperature measurements on Mount Etna lavas: problems and techniques, J. Volcanol. Geoth. Res., 1, 113-125.

Armienti, P., M.T. Pareschi, F. Innocenti and M. Pompilio (1994). Effects of magma storage and ascent on the kinetics of crystal growth, Contrib. Mineral. Petr., 115, 402-414.

Barberi, F., M. Rosi and A. Sodi (1993). Volcanic hazard assessment at Stromboli based on review of historical data, Acta Vulcanologica, 3, 173-187.

Behncke, B., S. Falsaperla and E. Pecora (2009). Complex magma dynamics at Mount Etna revealed by seismic, thermal and volcanological data, J. Geophys. Res., 114, B03211.

Calvari, S., M. Coltelli, M. Neri, M. Pompilio and V. Scribano (1994), The 1991-93 Etna eruption: chronology and lava flow field evolution, Acta Vulcanologica, 4, 1-14.

Chen, P.Y., R. Srinivasan, G. Fedosejevs and B. Narasimhan (2002). An automated cloud-detection method for daily NOAA-14 AVHRR data for Texas, USA, Int. J. Remote
Sens., 23, 2939-2950.

Colin, O., M. Rubio, P. Landart and E. Mathot (2007). VoMIR: Over 300 Volcanoes Monitored in Near RealTime by AATSR, In: H. Lacoste and L. Ouwehand (eds.), Proceedings of the Envisat Symposium 2007, Montreux, Switzerland, 23-27 April 2007 (ESA SP-636, July 2007).

Crisp, J. and S. Baloga (1990a). A model for lava flows with two thermal components, J. Geophys. Res. 95, 1255-1270.

Crisp, J. and S. Baloga (1990b). A method for estimating eruption rates of planetary lava flows, Icarus, 85, 512-515.

Dozier, J. (1981). A method for satellite identification of surface temperature fields of subpixel resolution, Remote Sens. Environ., 11, 221-229.

Flynn, L.P., P.J. Mouginis-Mark, J.C. Gradie and P.G. Lucey (1993). Radiative Temperature Measurements at Kupaianaha Lava Lake, Kilauea Volcano, Hawaii, J. Geophys. Res., 98 (B4), 6461-6476; doi: 10.1029/92JB02698.

Flynn, L.P. and P.J. Mouginis-Mark (1994). Temperature of an active lava channel from spectral measurements, Kilauea Volcano, Hawaii, B. Volcanol., 56, 297-301.

Ganci, G., A. Vicari, L. Fortuna and C. Del Negro (2011). The HOTSAT volcano monitoring system based on combined use of SEVIRI and MODIS multispectral data, Annals of Geophysics, 54 (5), 544-550 (this issue).

Glaze, L., P.W. Francis and D.A Rothery (1989). Measuring thermal budgets of active volcanoes by satellite remote sensing, Nature, 338, 144-146.

Harris, A.J.L., A.L. Butterworth, R.W. Carlton, I. Downey, P. Miller, P. Navarro and D.A. Rothery (1997a). Low-cost volcano surveillance from space: case studies from Etna, Krafla, Cerro Negro, Fogo, Lascar and Erebus, B. Volcanol. 59, 49-64.

Harris, A. J. L., S. Blake, D.A. Rothery and N.F. Stevens (1997b). A chronology of the 1991 to 1993 Mount Etna eruption using advanced very-high-resolution radiometer data: implications for real-time thermal volcano monitoring, J. Geophys. Res., 102, 7985-8003.

Harris, A.J.L., L.P. Flynn, L. Keszthelyi, P.J. Mouginis-Mark, S.K. Rowland and J.A. Resing (1998),. Calculation of lava effusion rates from Landsat TM data, B. Vulcanol., 60, 52-71.

Harris, A.J.L., L.P. Flynn, D.A. Rothery, C. Oppenheimer and S.B. Sherman (1999). Mass flux measurements at active lava lakes: implications for magma recycling, J. Geophys. Res., 104, 7117-7136.

Harris, A.J.L., J.B. Murray, S.E. Aries, M.A. Davies, L.P. Flynn, M.J. Wooster, R. Wright and D.A. Rothery (2000). Effusion rate trends at Etna and Krafta and their implications for eruptive mechanisms, J. Vulcanol. Geoth. Res., 102, 237-269.

Harris, A.J.L., E. Pilger, L.P. Flynn, H. Garbeil, P.J. MouginisMark, J. Kauahikaua and C. Thornber (2001). Automated, high-temporal-resolution, thermal analysis of Kilauea volcano, Hawaii, using GOES satellite data, Int. J. Remote 
Sens., 22, 945-967.

Harris, A.J.L., R. Carniel and J. Jones (2005). Identification of variable convective regimes at Erta Ale lava lake, J. Vulcanol. Geoth. Res., 142, 207-223.

Huppert, H.E. and R.S.J. Sparks (1988). Melting the roof of a chamber containing a hot, turbulently convecting fluid, J. Fluid Mech., 188, 107-131.

Keszthelyi, L., A.J.L. Harris and J. Dehn (2003). Observation of the effect of wind on the cooling of active lava flows, Geophys. Res. Lett., 30 (19), 1989; doi: 10.1029/2003GL017994.

Kilburn, C.R.J. (1990). Surfaces of 'a'a flow-fields on Mount Etna, Sicily: morphology, rheology, crystallization and scaling phenomena, In: J.H. Fink (ed.), Lava Flows and Domes: Emplacement Mechanisms and Hazard Implications (I a V C E I Proceedings in Volcanology), SpringerVerlag, 129-156.

Kilburn, C.R.J. and J.E. Guest (1993). 'a'a lavas of Mount Etna, Sicily, In: C.R.J. Kilburn and G. Luongo (eds.), Active Lavas: Monitoring and Modeling, Univ. College of London Press, 73-106.

Lipman, P.W. and N.G. Banks (1987). Aa flow dynamics, Mauna Loa 1984, U.S.G.S. Professional Paper N. 1350, 1527-1567.

Lombardo, V., M.F. Buongiorno, L. Merucci and D.C. Pieri (2004). Differences in Landsat TM derived lava flow thermal structure during summit and flank eruption at Mount Etna, J. Volcanol. Geoth. Res., 134, 15-34.

Lombardo, V. and M.F. Buongiorno (2006). Lava flow thermal analysis using three infrared bands of remote sensing imagery: a study case from Mt.Etna 2001 eruption, Remote Sens. Environ., 101 (2), 141-149.

Lombardo, V., M.F. Buongiorno and S. Amici (2006). Characterization of volcanic thermal anomalies by means of sub-pixel temperature distribution analysis, B. Volcanol., 68, 641-651.

Lombardo, V., A.J.L. Harris, S. Calvari and M.F. Buongiorno (2009). Spatial variations in lava flow field thermal structure and effusion rate derived from very high spatial resolution hyperspectral (MIVIS) data, J. Geophys. Res., 114, B02208; doi: 10.1029/2008JB005648.

Marchese, F., C. Filizzola, N. Genzano, G. Mazzeo, N. Pergola and V. Tramutoli (2011), Assessment and improvement of a robust satellite technique (RST) for thermal monitoring of volcanoes, Remote Sens. Environ., 115, 1556-1563.

Neri, M., F. Mazzarini, S. Tarquini, M. Bisson, I. Isola, B. Behncke and M.T. Pareschi (2008). The changing face of Mount Etna's summit area documented with LiDAR technology, Geophys. Res. Lett., 35, L09305; doi: 10.1029/ 2008 GL033740.

Oppenheimer, C. (1991). Lava flow cooling estimated from Landsat Thematic Mapper infrared data: the Lonquimay eruption (Chile, 1989). J. Geophys. Res., 96, 21865-21878.
Oppenheimer, C. (1993). Thermal distributions of hot volcanic surfaces constrained using three infrared bands of remote sensing data, Geophys. Res. Lett., 20, 431-434.

Oppenheimer, C., P.W. Francis, D.A. Rothery, R.W.T. Carlton and L. Glaze (1993a). Infrared image analysis of volcanic thermal features: Làscar Volcano, Chile, 1984-1992, J. Geophys. Res., 98, 4269-4286.

Oppenheimer, C., D.A. Rothery and P.W. Francis (1993b). Thermal distribution at fumarole fields: implications for infrared remote sensing of active volcanoes, J. Volcanol. Geoth. Res., 55, 97-115.

Patrick M., J. Dehn and K. Dean (2005). Numerical modeling of lava flow cooling applied to the 1997 Okmok eruption, II: Comparison with AVHRR thermal imagery, J. Geophys. Res., 110, B02210; doi: 10.1029/2003JB002538.

Pergola, N., F. Marchese and V. Tramutoli (2004). Automated detection of thermal features of active volcanoes by means of infrared AVHRR records, Remote Sens. Environ., 93, 311-327.

Pieri, D.C. and S. Baloga (1986). Eruption rate, area and length relationships for some Hawaiian lava flows, J. Volcanol. Geoth. Res., 30, 29-45.

Pieri, D.C., L.S. Glaze and M.J. Abrams (1990). Thermal radiance observation of an active lava flow during the June 1984 eruption of Mt. Etna, Geology, 18, 1018-1022.

Rothery, D.A., P.W. Francis and C.A. Wood (1988) Volcano monitoring using short wavelength infrared data from satellites, J. Geophys. Res., 93, 7993-8008.

Silvestri, M., M. Musacchio, F. Doumaz and F. Caprara (2008). Sviluppo di software per il controllo automatico di macchine UNIX dedicate alla ricezione e archiviazione di dati satellitari relativi alla stazione NOAA TERASCAN, Rapporti Tecnici INGV, 58, 27 pp.

Spinetti C., M.F. Buongiorno, S. Amici, V. Lombardo, A.J.L. Harris, A. Steffke, M. Musacchio and F. Doumaz (2008) Monitoring the $2006 \mathrm{Mt}$. Etna eruption by NOAAAVHRR and NASA-MODIS satellite data, Presented at IAVCEI General Assembly (Reykjavík, Iceland, August 2008), Session $4 \mathrm{f}$.

Spinetti C., F. Doumaz and M.F. Buongiorno (2010). Dallo spazio al territorio: un sistema di Osservazione della Terra in tempo reale, GEOmedia, 2/2010, 6-10.

Spangenberg, D.A., D.R. Doelling, V. Chakrapani, P. Minnis and T. Uttal (2002). Nighttime Cloud Detection Over the Arctic Using AVHRR Data, In: Proceedings of the Twelfth Atmospheric Radiation Measurement (ARM) Science Team Meeting (St. Petersburg, Florida, April 8-12, 2002).

Vicari A., A. Ciraudo, C. Del Negro, A. Hérault and L. Fortuna (2009). Lava flow simulations using discharge rates from thermal infrared satellite imagery during the 2006 Etna eruption, Nat. Hazards, 50 (3), 539-550; doi: 10.1007 / s11069-008-9306-7.

Wadge, G. (1977). The storage and release of magma on 
Mount Etna, J. Volcanol. Geoth. Res., 2, 361-384.

Wadge, G. (1981). The variation of magma discharge during basaltic eruptions, J. Volcanol. Geoth. Res., 11 (2-4), 139-168.

Walker, G.P.L. (1973). Lengths of lava flows, Philos. T. R. Soc. London, A274, 107-118.

Wan, Z. and J. Dozier (1989). Land-surface temperature measurement from space: physical principles and inverse modelling, IEEE T. Geosci. Remote, 27, 268-277.

Webley, P.W., M.J. Wooster, W. Strauch, J.A. Saballos, K. Dill, P. Stephenson, J. Stephenson, R. Escobar Wolf and O. Matias (2008). Experiences from near-real-time satellitebased volcano monitoring in central America: case studies at Fuego, Guatemala, Int. J. Remote Sens., 29, 6621-6646; doi: 10.1080/01431160802168301.

Wooster, M.J. and D.A. Rothery (1997). Time series analysis of effusive volcanic activity using the ERS along track scanning radiometer: the 1995 eruption of Fernandina volcano, Galapagos Island, Remote Sens. Environ., 69, 109-117.

Wright, R, D.A. Rothery, S. Blake and D.C. Pieri (2000). Improved remote sensing estimates of lava flow cooling: a case study of the 1991 to 1993 Mount Etna eruption, J. Geophys. Res. 105, 23681-23694.

Wright, R., S. Blake, A. Harris and D. Rothery (2001). A simple explanation for the space-based calculation of lava eruptions rates, Earth Planet. Sci. Lett., 192, 223-233.

Wright, R., L. Flynn, H. Garbeil, A. Harris and E. Pilger (2004). MODVOLC: near-real-time thermal monitoring of global volcanism, J. Volcanol. Geoth. Res. 135, 29-49.

\footnotetext{
${ }^{\star}$ Corresponding author: Valerio Lombardo, Istituto Nazionale di Geofisica e Vulcanologia, Centro Nazionale Terremoti, Rome, Italy; email: valerio.lombardo@ingv.it.

(C) 2011 by the Istituto Nazionale di Geofisica e Vulcanologia. All rights reserved.
} 